\title{
Nongovernmental organizations and social aspects of COVID-19 pandemic: A successful experience in health policy
}

\author{
Mahasti Alizadeh $^{1}$, Madineh Abbasi ${ }^{2}$, Narges Bashirivand ${ }^{1}$, Atefe Mojtahed ${ }^{1}$, Salah Eddin Karimi*1(D) \\ Received: 3 Jul 2020 \\ Published: 16 Dec 2020
}

\section{Abstract}

Background: This study aimed to provide information on activities and experiences of Nongovernmental organizations in Tabriz regarding COVID-19 to develop a framework for effective measures and actions for other communities based on relevant achievements and experiences.

Method: The Social determinants of health research center of Tabriz University of Medical Sciences coordinated the NGOs to deal with the consequences of COVID-19 disease by announcing, inviting, developing networks and preparing aims and objectives and action plans in participation with the NGOs.

Results: This cooperation and synergy among NGOs led to following results: providing public health education, fund raising to provide health service and food items for vulnerable families, advocacy by writing letters to the governor and the City Council and emphasizing the needs for controlling the epidemics.

Conclusion: NGOs can increase public awareness, change social policies, and provide services and facilities to the vulnerable groups of people to deal with these problems.

Keywords: COVID-19, Pandemic, Social aspect, Health policy, Nongovernmental organization, Social determinants

\author{
Conflicts of Interest: None declared \\ Funding: None
}

\section{*This work has been published under CC BY-NC-SA 1.0 license. \\ Copyright $₫$ Iran University of Medical Sciences}

Cite this article as: Alizadeh M, Abbasi M, Bashirivand N, Mojtahed A, Karimi SE. Nongovernmental organizations and social aspects of COVID-19 pandemic: A successful experience in health policy. Med J Islam Repub Iran. 2020 (16 Dec);34:170. https://doi.org/10.47176/mjiri.34.170

\section{Introduction}

Experiences which have been gained during a 50-year period in various countries and relevant studies have shown that governments cannot meet the needs of the people alone

Corresponding author: Dr Salah Eddin Karimi, sa.karimi@uswr.ac.ir

1. Social Determinants of Health Research Center, Health Management and Safety Promotion Research Institute, Tabriz University of Medical Sciences, Tabriz, Iran 2. Infectious and Tropical Diseases Research Center, Tabriz University of Medical Sciences, Tabriz, Iran
$(1,2)$. Thus, nongovernmental organizations (NGOs) were established to resolve the ensued crises, including the problems after the Second World War, famines and financial

\section{$\uparrow$ What is "already known" in this topic:}

Is it possible to take public health measures and implement public health policies in the fight against COVID-19 with the help of the nongovernmental organizations?

COVID-19 is essentially a social problem largely because it stems from social causes and has social consequences.

The social nature of COVID-19 highlights the fact that all of the social capacities, including nongovernmental organizations, should be used to prevent and control it.

\section{$\rightarrow$ What this article adds:}

This study aimed to provide information on the activities and experiences of nongovernmental organizations in Tabriz-Iran regarding COVID-19 to develop a framework for effective measures and actions for other communities based on the relevant achievements and experiences in this city. 
crises, the collapse of the Eastern bloc, endangerment of the environment, natural disasters, and diseases (1-3). NGOs refer to the voluntary nonprofit groups of citizens which are established locally, nationally, and internationally for a wide range of cultural, social, charitable, professional, and trade union purposes (4). These organizations can perform an active role in all areas. In the realm of health, governments have been inclined to seek help from NGOs and people to improve public access to health resources due to change in the health system procedure in the 1990s and reduction in the health budget, which affected the quality of health care services. Nonetheless, 3 articles of the Declaration of Alma-Ata emphasized the people's actions and participation in health: encouraging and increasing the participation of the community, creating supportive environments, and empowering the individuals $(5,6)$.

NGOs can perform a significant role in the prevention, control, and resolution of the social problems. Social issues comprise a wide range, including environment, education, poverty, unemployment, social services, health, and diseases. It is difficult to improve public health and social health, especially in times of crisis, without the help of NGOs (7). Studies have shown NGOs have fulfilled a major role in the implementation of following health programs: control of smoking (8) and infectious and epidemic diseases (for instance: media campaigns); provision of counseling and access to condoms; provision of services to vulnerable and sensitive cultural groups such as sex workers, prisoners, and immigrants who suffer from HIV / AIDS $(9,10)$; prevention of malaria (5); improvement of women's health (11); treatment of burn wounds (12); decrease in infant mortality (13); procurement of equipment, facilities, medicine, and medical supplies (14); identification of tuberculosis patients and provision of tuberculosis care (15); provision of relief and acceleration of the reconstruction process during and after earthquakes $(16,17)$ waste management $(18,19)$; and provision of services to mental patients (20). In this regard, the World Development Report of World Bank in 1993 called for policies on investment in health care. These policies should focus on NGOs to motivate them to include a variety of health care services and to compete to provide these services (21). This issue stems from the importance of the provision of support for vulnerable people, especially when there is an outbreak of a disease. Vulnerable people will be under financial pressure due to the disease even if they have health insurance. Moreover, their job and source of income will be affected by the length of quarantine (22).

The policies of public health aim to increase social participation and to receive assistance from NGOs to improve health. This issue raises the following question: Is it possible to take public health measures and implement public health policies in the fight against COVID-19 with the help of NGOs?

COVID-19, a virus which causes the acute respiratory syndrome, was found in Wuhan (China) in December 2019, with no effective treatment or vaccine to prevent it. Consequently, preventing its spread by quarantining cases, tracking patients' contact with other members of the society to reduce mortality and protect the elderly and the patients who need special care are the best ways to prevent it (23, 24). The preliminary data from China showed most of the patients who worked in or around the seafood and animal markets (25). COVID-19 is biological in origin, but it is essentially a social problem as it has social consequences. COVID-19 stems from social causes since it depends on the food culture, lifestyle, and level of social communication. These factors transmit the disease from the patients to the other members of the society and contribute to its spread. Moreover, COVID-19 has certain social consequences because it has become an epidemic and has created mass stress. Furthermore, it has caused problems for the whole community and the NGOs and disrupted social activities. In addition, the social effects of COVID-19 will be noticeable in the post-COVID-19 period. Poverty is one of the most enduring effects of this virus. The social nature of COVID-19 highlights the fact that social capacities, including NGOs, should be used to prevent and control it.

One of the main reasons behind the spread of COVID19 is the lack of knowledge about the ways by which the virus is transmitted. NGOs can increase public awareness, change social policies, and provide services and facilities to the vulnerable groups of people to deal with these problems. Based on these issues, this study aimed to provide information on activities and experiences of NGOs in Tabriz regarding COVID-19 to develop a framework for effective measures and actions for other communities based on relevant achievements and experiences in Tabriz.

The Social determinants of health research center of Tabriz University of Medical Sciences coordinated the NGOs to deal with the consequences of COVID-19 disease. The serious and epidemic risks of this virus highlighted the fact that at least $70 \%$ of the population faced the risk of infection. Consequently, the aforementioned research center called for effective interventions, encouraged the public participation, and made an endeavor to use the social, economic and cultural resources of the activists.

The stages of this movement were as follow:

1. Inviting all real and legal persons in the field of public health, including all the NGOs in different cities of the relevant province, social activists, faculty members of universities, volunteers, doctors and psychologists, knowledgeable and influential marketers, students, and scientific associations to participate in the People's Movement to Restrain COVID-19 Committee (PMRC).

2. The cyberspace (ie, forming WhatsApp and Instagram groups with 900 members on March 8, 2020 under the name of People's Movement to Restrain COVID-19) was used to coordinate the planning and summarize the suggestions and solutions due to the restrictions of face-to-face meetings and normal sessions.

3. Developing aims and objectives of the PMRC

4. Developing action plan and groups for accomplishing each action plan

\section{NGOs}

These groups attempted to achieve the following purposes:

1) Develop the synergy among NGOs

2) Identify major problems to control COVID-19 
3) Build consensus and encouraging the organizations and individuals to exchange their views to find solutions to main problems

4) Develop the synergy between organizations and individuals regarding the implementation of the agreed plans

The proposed programs and plans were encapsulated in a number of recommendations after summarizing and prioritizing the collected activities:

1) Divide the vulnerable neighborhoods and the suburbs between the NGOs and the individuals to assist people in these areas, provide public health education, and advise about effective ways of preventing the spread of the disease

2) Have access to influential individuals in various neighborhoods and encouraging the cooperation between religious groups, mosques, health centers, and local marketers to convey the messages to people, encourage them to take COVID-19 seriously, reduce traffic and travels, and motivate people to join the Stay-at-Home campaign in Nowruz (Iranian New Year) holidays

3) Raise funds to provide health service and food items for vulnerable families and families who live in the suburbs based on the information of NGOs

4) Raise funds to provide protective equipment for medical staff, patients who need special care, and vulnerable people

5) Cooperate with Provincial Television Network and the local radio station to inform the public about the disease due to the wide audience of these media, especially in the suburbs and villages, where access to the internet is limited or impossible

6) Provide health care education for the vulnerable individuals with the help of NGOs and assistance and rehabilitation clinics

7) Encourage cooperation between popular individuals and groups such as sports teams and artists to motivate people to take COVID-19 seriously and reduce the spread of this disease

8) Reduce city traffic by temporarily closing nonessential businesses such as barber shops and beauty salons, gyms, shopping malls, and street vendors

At the next stage, based on the agreed plans, the research center coordinated the volunteers to take measures to prevent the transmission of COVID-19, which were as follow:

1) Correspondence to COVID-19 Management and Control Headquarters by writing a letter to the governor and the City Council and emphasizing the needs: (a) close nonessential businesses; (b) facilitate activities of food and health businesses; (c) stop unnecessary business activities offices, including dangerous municipal activities (eg, planting trees), and banks; (d) encourage distance working; (e) close shopping malls and stores except essential stores; (e) not allowing Nowruz travelers to enter the city and discourage them from choosing Tabriz as their destination; (f) stop the intracity and intercity taxis and buses and stop domestic and international flights; g) ensure the safety of the medical staff; h) fight the virus in the city entrances instead of the hospitals; and i) control the intracity and intercity traffic

2) Communicate with Tabriz Bazaar Network, emphasize the seriousness of the danger of the virus, and highlight the importance of the assistance of the above-mentioned network to control the disease and prevent the spread of the virus in Tabriz

3) Create a virtual network for mothers and women who act as health messengers and increase awareness about the dangers of the spread of the COVID-19 virus in neighborhoods

4) Create local and rural networks to control and restrict individuals in local and weekly markets

5) Launch the \# Let's-Help-to-Maintain-Health campaign as follows:

(a) Building public teams to provide masks and health care equipment with the help of charities and generous entrepreneurs that cooperate with hospitals to disinfect, standardize, and sterilize them and donating clothes and masks to hospitals and patients who need special care

b) Launching the \# Thanks-to-the-Health-Workers campaign with the help of Tabriz Charity Institute. They are exhausted because they work around the clock. Tabriz Charity Institute reached an agreement with the National Public Health Management Center (NPMC) and decided to provide welfare services to the medical staff and provide them with a place to rest.

6) Launch a professional campaign to provide people with psychological support and implement effective and therapeutic interventions to deal with the psychological consequences of the new virus, and providing psychological support to the individuals and families who have lost their loved ones. This professional campaign was launched with the help of psychologists and psychiatrists

7) Launch the \# Stay-at-Home campaign: creating informative networks to increase people's awareness about COVID-19 and taking preventive measures to reduce the spread of the diseases in the suburb of Tabriz and in the neighborhoods which do not have enough economic, social, and cultural facilities and resources.

8) Launch the \# Let-Us-Help-Them-Stay-at-Home campaign: the living supplies-health packages were provided for low-income groups or those whose income depend on daily wages, including women responsible for their households, families of the prisoners, women who have been deserted by their husband, and young girls who live on their own in vulnerable neighborhoods of Tabriz to provide food, health care, and welfare services for themselves.

9) Inform people about the disease using virtual networks and active news agencies in the province

10) Spread health messages and warnings about the disease in the neighborhoods with the help of local marketers and trusted people in the neighborhoods

11) Seek financial aid and support of human resources to make masks for the medical staff in hospitals and provide them with health care and protective equipment

12) Form a counseling and educational group for women named "mothers who maintain family health" to provide accurate educational content

13) Provide masks and health care equipment for those patients who need special care, for garbage collectors, and for parking attendants

14) Conduct the March, 19, 2020 campaign by meeting the safety requirements, maintaining social distance, and 
spray alcohol and sodium hypochlorite in the neighborhoods and streets with the help of the police and the army; some of the results of such action were as follow:

1. Provide food and other basic needs for more than 2000 families

2. Make face masks for more than 5000 people and health workers

3. Organize educational campaigns for about 10000 people in different neighborhoods

4. Provide psychological support for about 100 families who lost their loved ones and about 200 families with a COVID-19 patient

\section{Conflict of Interests}

The authors declare that they have no competing interests.

\section{References}

1.Daynes L. Communicating Suffering: A View from NGO Practice. InCaring in Crisis? Humanitarianism, the Public and NGOs 2017 (pp. 119-123). Palgrave Macmillan, Cham.

2. Yan X, Lin H, Clarke A. Cross-sector social partnerships for social change: The roles of non-governmental organizations. Sustainability. 2018 Feb;10(2):558

3. Amir Kavasemi A. A Study of the Causes of Increasing Growth of NonGovernmental Organizations. Q Int Social. 2009;20(5):pp2532.[persian].

4.Zahedi M. Roles of NGOs in sustainable development1th Edition, Maziar Publication: Tehran, 2009. [Persian]

5. Muriuki DW. Contribution of NGOs in complex emergencies humanitarian health action. InWorld Health Organization Conference on the Health Aspects of the Tsunami Disaster in Asia, Phuket, Thailand 2005.

6. World Health Organization. A WHO plan for burn prevention and care. World Health Organization; 2008.

7. Lempert $\mathrm{D}$, Nguyen HN. A sustainable development indicator for NGOs and international organisations. Int J Sustain Society. 2008 Jan $1 ; 1(1): 44-54$.

8. Lencucha R, Kothari A, Labonté R. The role of non-governmental organizations in global health diplomacy: negotiating the Framework Convention on Tobacco Control. Health Policy and Plan. 2011 Sep 1;26(5):405-12.

9. Benotsch EG, Stevenson LY, Sitzler CA, Kelly JA, Makhaye G, Mathey $\mathrm{ED}$, et al. HIV prevention in Africa: programs and populations served by non-governmental organizations. J Commun Health. 2004 Aug 1;29(4):319-36.

10. Odindo MA, Mwanthi MA. Role of governmental and nongovernmental organizations in mitigation of stigma and discrimination among HIV/AIDS persons in Kibera, Kenya. East Afr Public Health. 2008 Apr;5(1):1-5.

11. Mercer AM, Uddin N, Huq NL, Haseen F, Khan MH. Larson CP. Validating Neo-Natal Mortality and Use of Non-Governmental Organization Reproductive Health Outreach Service in Rural Bangladesh. Stud Fam Plann. 2006;37:111-22.

12. Fabia R, Gallagher J, Wheeler KK, Johnson M, Cadelski K, Armstrong $\mathrm{M}$, et al. Efforts to catalogue non-governmental organizations with a role in global burn relief. Burns. 2020 Mar 9.

13. Shandra JM, Shandra CL, London B. Do non-governmental organizations impact health? A cross-national analysis of infant mortality. Int J Comp Sociol. 2010 Feb;51(1-2):137-64.

14. Otchere S, Ransom E. Bringing care closer to mothers and newborns: using the gap analysis tool to develop a household to hospital continuum of care. Washington, DC, USA: Save the Children. 2005.

15. Maung HM, Saw S, Isaakidis P, Khogali M, Reid A, Hoa NB, et al. The contribution of a non-governmental organisation's Community Based Tuberculosis Care Programme to case finding in Myanmar: trend over time. Infect Dis Poverty. 2017 Dec 1;6(1):51.

16. $\mathrm{Lu} \mathrm{Y}, \mathrm{Xu} \mathrm{J}$. NGO collaboration in community post-disaster reconstruction: field research following the 2008 Wenchuan earthquake in China. Disasters. 2015 Apr;39(2):258-78.

17. Fallah S. The Role of Non-Governmental Organizations in Disaster
Management: A Case study of Bam Earthquake, Iran. J Disaster and Emerg Res. 2018 Mar 10;1(1):43-50.

18. Ahsan A, Alamgir M, Imteaz M, Daud NN, Islam R. Role of NGOs and CBOs in waste management. Iran J Public Health. 2012;41(6):27.

19. Rajamanikam R, Poyyamoli G, Kumar S. The role of nongovernmental organizations in residential solid waste management: A case study of Puducherry, a coastal city of India. Waste Manag Res. 2014 Sep;32(9):867-81.

20. Rose G, von Hippel C, Brener L, von Hippel B. Attitudes of people working in mental health non-governmental organisations in Australia: A comparison with other mental health professionals. Health Psychol Open. 2018 Apr;5(1):2055102918765413.

21. Gilson L, Sen PD, Mohammed S, Mujinja P. The potential of health sector non-governmental organizations: policy options. Health Policy Plann. 1994 Mar 1;9(1):14-24.

22. Zhicheng Wang and Kun Tang, Combating COVID-19: health equity matters, Published: 26, March, 2020. https://doi.org/10.1038/s41591020-0823-6.

23. Young BE, Ong SW, Kalimuddin S, Low JG, Tan SY, Loh J, et al. Epidemiologic features and clinical course of patients infected with SARS-CoV-2 in Singapore. JAMA. 2020 Mar 3.

24. Editorial. COVID-19: learning from experience. March 28, 2020;395(10229):1011-1088.

25. Chen N, Zhou M, Dong X, Qu J, Gong F, Han Y, et al. Epidemiological and clinical characteristics of 99 cases of 2019 novel coronavirus pneumonia in Wuhan, China: a descriptive study. Lancet. 2020 Feb 15;395(10223):507-13. 